\title{
Efektivitas Penerapan Program Kawasan Rumah Pangan Lestari (KRPL) di Kelurahan Kampung Dalem Kota Kediri
}

\author{
Silvia Devi Sugiarto, Nurul Ahsin
}

Institut Agama Islam Negeri Kediri, Indonesia

silviadevi280@gmail.com, ahsin@iainkediri.ac.id

\begin{abstract}
Community empowerment through the "Sustainable Food Houses" (KRPL) program is one of the efforts of the Ministry of Agriculture in meeting food needs. This program optimizes the use of home gardens as a source of family food through planting various vegetables, fruits, tubers and medicinal plants as well as raising livestock and fish. Household food security is a problem that must be considered so that food vulnerability does not occur due to the low independence of the community in meeting food needs. Judging from the uniqueness of this program, this research needs to be done to describe the level of effectiveness of the KRPL Program in Kampung Dalem Village, Kediri City. Because this area is one of the villages that has participated in implementing the KRPL Program since 2017. This research method uses a qualitative descriptive analysis approach. Data collection techniques through observation and interviews with members of the KRPL group. While the data analysis uses flow data analysis (flow model), namely the analysis model with data reduction techniques, data presentation, and drawing conclusions. Based on data processing, the results of this study indicate that the implementation of the KRPL program in Kampung Dalem Village, Kediri City has been running effectively. This is due to several supporting factors, including the right program targets; effective and massive methods of socialization, willingness and ability of members in implementing the program, as well as the utilization of the results of the program that can be felt directly by members in meeting household food needs.
\end{abstract}

Keywords: Food, Sustainable Food House Area (KRPL), Effectiveness

Abstrak: Pemberdayaan masyarakat melalui program "Rumah Pangan Berkelanjutan" (KRPL) merupakan salah satu upaya Kementerian Pertanian dalam memenuhi kebutuhan pangan. Program ini mengoptimalkan penggunaan kebun rumah tangga sebagai sumber makanan keluarga melalui penanaman berbagai sayuran, buah-buahan, umbi-umbian dan tanaman obat serta memelihara ternak dan ikan. Ketahanan pangan rumah tangga merupakan masalah yang harus diperhatikan agar kerentanan pangan tidak terjadi akibat rendahnya kemandirian masyarakat dalam memenuhi kebutuhan pangan. Dilihat dari keunikan program ini, penelitian ini perlu dilakukan untuk menggambarkan tingkat efektivitas Program KRPL di Kelurahan Kampung Dalem, Kota Kediri. Karena daerah ini merupakan salah satu desa yang telah berpartisipasi dalam melaksanakan Program KRPL sejak tahun 2017. Metode penelitian ini menggunakan pendekatan analisis deskriptif kualitatif. Teknik pengumpulan data melalui observasi dan wawancara dengan anggota kelompok KRPL. Sedangkan analisis data menggunakan flow data analysis (flow model), yaitu model analisis dengan teknik pengurangan data, presentasi data, dan kesimpulan gambar. Berdasarkan pengolahan data, hasil penelitian ini menunjukkan bahwa pelaksanaan program KRPL di Kampung Dalem, Kota Kediri sudah berjalan efektif. Hal ini disebabkan oleh beberapa faktor pendukung, termasuk target program yang tepat; metode sosialisasi yang efektif dan masif, kemauan dan kemampuan anggota dalam melaksanakan program tersebut, serta pemanfaatan hasil program 
JoIE: Journal of Islamic Economics | Silvia Devi Sugiarto, Nurul Ahsin

P-ISSN : 2807-7377

E-ISSN : 2807-7091

yang dapat dirasakan langsung oleh anggota dalam memenuhi kebutuhan pangan rumah tangga.

Kata Kunci: Pangan, Kawasan Rumah Pangan Berkelanjutan (KRPL), Efektivitas

\section{PENDAHULUAN}

Dalam mempertahankan kemandirian pangan, pemerintah harus maksimal dalam memberikan kebutuhan pangan masyarakat melalui hal apapun itu. Sebagaimana yang harus diketahui oleh pemerintah, kemandirian pangan dapat dicirikan melalui tercukupnya kebutuhan pangan yang mengandung gizi yang banyak untuk kesehatan tubuh. Program Kawasan Rumah Pangan Lestari (KRPL) merupakan program yang dibangun oleh Tubuh Ketahanan Pangan (BKP) untuk meminimalisir kerawanan pangan masyarakat, pelaksanaan program KRPL dibiayai oleh dana Bantuan Pemerintah melalui dekonsentrasi diprovinsi (Tamara et al., 2020). Program ini sangat membutuhkan peran masyarakat dan pemerintah agar dapat bekerjasama secara kreatif dan dapat berfungsi sebagai langkah memperkuat ketahanan pangan dan mengembangkan potensi kuliner daerah (Rahmawati \& Parangu (2021).

Pemanfaatan lahan kosong dapat diolah menjadi sumber yang menghasilkan ekonomi tinggi yang dapat mensejahterakan ekonomi masyarakat serta dapat pula menjadi sumber potensi penghasil bahan pangan. Melalui aktivitas KRPL inilah nantinya, masyarakat memanfaat lahan kosong atau pekarangan kosong yang berada di lingkungan rumah untuk ditanami beberapa jenis sayuran, ataupun tanaman obat keluarga (toga) yang dapat dimanfaatkan untuk kebutuhan kesehatan. Kemandirian pangan dapat berjalan dengan baik dimulai dari aktivitas rumah tangga dalam pemanfaatan pekarangan kosong yang diolah menjadi sumber pangan. Implementasi KRPL dapat dijadikan suatu kebiasaan masyarakat dalam manifestasi perilaku pelestarian dan peduli lingkungan (Sholehah et al., 2016). Berlandaskan hal tersebut Kementerian Pertanian menggerakkan konsep pemanfaatan pekarangan melalui program Kawasan Rumah Pangan Lestari KRPL. Hasil dari usaha pekarangan diharpakan dapat memberikan kontribusi sebagaimana kebutuhan konsumsi rumah.

Tujuan utama Kementerian Pertanian memiliki tujan utama dengan adanya program Kawasan Rumah Pangan Lestari (KRPL), yaitu: (1) Pemanfaatan pekarangan rumah guna memenuhi kebutuhan gizi pangan masyarakat, (2) meningkatkan keahlian masyarakat dalam menanam berbagai jenis buah, sayuran, ataupun berbagai jenis macam toga yang ada, 
JoIE: Journal of Islamic Economics | Silvia Devi Sugiarto, Nurul Ahsin

P-ISSN : 2807-7377

E-ISSN : 2807-7091

pemeliharaan ternak dan ikan, pengolahan limbah rumah tangga menjadi pupuk kompos, (3) memaksimalkan pelestarian tumbuhan pangan untuk masa depan masyarakat, (4) untuk mencapai kesejahteraan keluarga melalui ekonomi produktif, serta dapat menghasilkan lingkungan hijau secara mandiri (Mayusa et al., 2018).

Pada awalnya anggota KRPL memiliki antusiasme dan semangat yang tinggi dalam menjalankan Program KRPL ini dilihat dari keaktifan anggota dalam mengelola tanaman, namun seiring berjalannya waktu kegiatan anggota KRPL Subur Makmur sudah tidak seaktif dulu. Hal ini disebabkan kesibukkan dan kejenuhan anggota dalam mengelola tanaman, mengingat tanaman sayur yang ditanaman harus memerlukan perawatan yang optimal. Tidak adanya pemantauan dari pihak luar yang terkait program KRPL ini, menjadi salah satu penyebab menurunnya aktivitas kelompok KRPL Subur Makmur, maka dari itu minimnya pemantauan dan pengawasan kegiatan program KRPL sulit berkembang dan tidak terjadi berkelanjutan.

\section{TINJAUAN LITERATUR}

\section{Konsep Kawasan Rumah Pangan Lestari (KRPL)}

Kawasan Rumah Pangan Lestari (KRPL) dilaksanakan melalui pergerakan memanfaatkan pekarangan atau lahan kosong di sekitar lingkungan rumah, dengan adanya pekarangan kosong nantinya dapat ditanami dengan beberapa tumbuhan yaitu berbagai jenis sayuran, buah-buahan, ataupun jenis tumbuhan keluarga (toga) serta dapat pula dimanfaatkan sebagai lahan ternak (Oka, I., Darmawan, Dwi., Astiti, 2016). Program KRPL ini tidak dapat dilakukan secara sendiri-sendiri (individu), dimulai dari perencanaan dan proses pelaksaan KRPL harus dilakukan secara berkelompok, oleh karena itu pentingnya masyarakat dan pemerintah. Setelah berhasil melakukan proses kegiatan KRPL, perlu dilakukan proses evaluasi dan penyempurnaan yang didampingi oleh penggerak atau penyuluh lapangan.

Program KRPL diharapkan dapat berjalan secara berkelanjutan secara lestari yang dapat membentuk kawasan rumah pangan untuk masa depan masyarakat. Menurut Simatupang melihat dari sistem hirarki mulai dari tingkat global, nasional, regional, wilayah, rumah tang dan individu perlu dilakukan bentuk terwujudnya ketahanan pangan (Purwami et al., 2018). Tentunya Program Kawasan Rumah Pangan Lestari harus memiliki dukungan dari berbagai pihak, terutama dari pihak masyarakat dan pemerintah sendiri, mulai dari tahap program hingga evaluasi program yang berkelanjutan. Program ini 
diharapkan Badan Litbang Pertanian dapat berkembang dan merata di seluruh kawasan Indonesia. Apabila program KRPL telah berjalan dengan baik, maka dapat meminimalisir kerawanan pangan masyarakat.

Tujuan dari KRPL adalah:

a. Pemanfaatan pekarangan rumah guna memenuhi kebutuhan gizi pangan masyarakat.

b. Meningkatkan keahlian masyarakat dalam menanam berbagai jenis buah, sayuran, ataupun berbagai jenis macam toga yang ada, pemeliharaan ternak dan ikan, pengolahan limbah rumah tangga menjadi pupuk kompos.

c. Memaksimalkan pelestarian tumbuhan pangan untuk masa depan masyarakat.

d. Untuk mencapai kesejahteraan keluarga melalui ekonomi produktif, serta dapat menghasilkan lingkungann hijau secara mandiri.

\section{Efektivitas}

Menurut Gie efektivitas merupakan suatu keadaan yang dapat terjadi apabila dikehendaki oleh seseorang (Kurniawan et al., 2018). Daya guna pula berhubungan dengan derajat keberhasilan sesuatu pembedahan pada bagian publik sehingga sesuatu aktivitas dikatakan efisien bila aktivitas tersebut memiliki pengaruh besar terhadap keahlian sediakan pelayanan publik yang menggambarkan target yang sudah didetetapkan.

Efektivitas merupakan tolak ukur keberhasilan pencapaian suatu organisasi dalam meraih tujuannya. Apabila tujuan organisasi telah berhasil mencapai tujuan maka organisasi tersebut berjalan efiesien. Efektivitas juga bisa menjadi penanda daya guna jangkauan akibat dan dampak dalam meraih tujuan organisasi. Semakin besar kontribusi maka semakin efektif suatu organisasi tersebut berjalan.

Jadi dapat diambil kesimpulkan dari definis efektivitas yaitu unsur utama yang dapat mempengaruhi suatu organisasi dalam mencapai tujuannya, melalui beberapa macam kegiatan ataupun program yang sudah terencanakan.

\section{Indikator Efektivitas Program}

Keefektivitas program dapat dinilai apabila suatu program ataupun kegiatan telah berjalan sesuai dengan tujuan yang telah dimiliki secara efektif dan efisien. Adapun beberapa indikator yang dapat digunakan dalam mengukur efektivitas, antara lain (Pembangunan, 2017):

a. Ketepatan sasaran program, merupakan seberapa jauh progam yang telah direncanakan sudah tepat tertuju kepada sasaran yang ditentukan. 
b. Sosialisasi program, merupakan informasi mengenai aktivitas yang akan dilakukan dapat tersampaikan dan dipahamai kepada masyrakat.

c. Tujuan Program, merupakan bagaimana keberhasilan program dengan tujuan program yang telah direncanakan sebelumnya.

d. Pemantauan Program, merupakan pemantauan yang dilakukan untuk melihat hasil perkembangan program yang telah terlaksana.

\section{METODE PENELITIAN}

\section{Jenis Penelitian}

Pada penelitian ini menggunakan jenis pendekatan kualitatif, karena dalam penelitian ini digunakan dengan tujuan untuk meneliti pada kondisi objek alamiah, dalam penelitian ini manusia sebagai instrumennya.

\section{Lokasi Penelitian}

Penelitian ini diadakan di Kawasan Rumah Pangan Lestari di Kelurahan Kampung Dalem Kota Kediri Provinsi Jawa Timur.

\section{Populasi dan Sampel}

Sampel yang digunakan dalam peneliatian ini adalah sebagian dari populasi jumlah warga di Kawasan Rumah Pangan Lestari di Kelurahan Kampung Dalem Kota Kediri Provinsi Jawa Timur. Terdapat lima belas anggota sebagai informan yang memberikan tanggapan terhadap pertanyaan yang diajukan. Dua belas anggota berjenis kelamin perempuan dan tiga anggota berjenis kelamin laki-laki.

\section{Teknik Pengambilan Data}

Teknik pengumpulan data dilakukan melalui observasi, dan wawancara mendalam secara langsung kepada anggota kelompok KRPL Subur Makmur. Setelah data terkumpul, lalu dilakukan analisis data dengan model analisis data mengalir (flow model).

\section{Analisis Penelitian}

Metode analisis yang digunakan dalam tulisan ini adalah metode penelitian deskriptif kualitatif, sejumlah langkah analisis terdapat dalam metode ini, yakni reduksi data, penyajian data, dan penarikan kesimpulan. 
JoIE: Journal of Islamic Economics | Silvia Devi Sugiarto, Nurul Ahsin

P-ISSN : 2807-7377

E-ISSN : 2807-7091

Dalam mempertahankan kemandirian pangan, pemerintah harus maksimal dalam memberikan kebutuhan pangan masyarakat melalui hal apapun itu. Sebagaimana yang harus diketahui oleh pemerintah, kemandirian pangan dapat dicirikan melalui tercukupnya kebutuhan pangan yang mengandung gizi yang banyak untuk kesehatan tubuh. Program Kawasan Rumah Pangan Lestari (KRPL) merupakan program yang dibangun oleh Tubuh Ketahanan Pangan (BKP) untuk meminimalisir kerawanan pangan masyarakat. Pemanfaatan lahan kosong dapat diolah menjadi sumber yang menghasilkan ekonomi tinggi yang dapat mensejahterakan ekonomi masyarakat serta dapat pula menjadi sumber potensi penghasil bahan pangan. Pada 2 Februari 2017 Kelurahan Kampung Dalem terbentuk Kawasan Rumah Pangan Lestari (KRPL) karena menjadi peserta lomba KRPL yang diadakan oleh Kota Kediri, dalam program ini dana operasional di dapat dari Anggaran Pendapatan dan Belanja Negara (APBN).Tentunya melalui program KRPL ini dapat dijadikan suatu upaya dalam menghadapi ketahanan pangan, terutama dimulai dari level rumah tangga.

Melalui program KRPL yang dilakukan selama 3 tahun ini, menimbulkan dampak positif dalam pelaksanaan Program KRPL di Kelurahan Kampung Dalem, yaitu masyarakat Kelurahan Kampung Dalem dapat memperoleh keuntungan dalam pemanfaatan lahan pekarangan kosong, hal utama yang dapat diambil dalam pemanfaatan hasil dari KRPL ini yaitu adanya kemajuan kualitas hidup masyarakat, dan dapat menunjang peningkatan nilai ekonomi. Hal itu dapat dirasakan pada saat aktu panen yang telah tiba. Secara mayoritas masyrakat Kampung Dalem menikmati manfaat dari hasil ini digunakan sebagai tambahan kebutuhan sehari-hari, sehingga dapat meminimalisisr pengeluaran yang digunakan untuk belanja pada setiap harinya

Disisi lain terdapat Program KRPL juga memiliki sisi negatif atau sebagai tantangan, yaitu menjaga agar berlanjutan kegiatan pemanfaatan pekarangan dalam Program KRPL ini. Maka dari itu perlu unntuk dilakukan penelitian terkait efektivitas program KRPL yang telah berjalan di wilayah Kelurahan Kampungg Dalem, melalui riset ini digunakan untuk mengetahui sejauh mana output dan tujuan telah berjalan. Selain hal tersebut, dapat mengetahui sejauh mana pancapaian yang sudah dilakukan sesuai dengan tujuan program KRPL.

Menurut Gie efektivitas merupakan suatu keadaan yang dapat terjadi apabila dikehendaki oleh seseorang. Semakin besar kontribusi nilai pencapaian tujuan lebih besar daripada kontribusi output, semakin efektif unit tersebut. Efektivitas program KRPL dalam penelitian ini bertujuan untuk mengukur efektivitas rencana KRPL di desa Kampung Dalem 
JoIE: Journal of Islamic Economics | Silvia Devi Sugiarto, Nurul Ahsin

P-ISSN : 2807-7377

E-ISSN : 2807-7091

berdasarkan indeks efektivitas, serta menganalisis kelebihan dan kekurangan pelaksanaan program KRPL di sana. Dalam variabel penelitian ini peneliti menggunakan satu variabel yaitu variabel validitas program.

Hasil yang didapat peneliti mengenai Efektivitas Program KRPL di Kelurahan Kampung

Dalem Kota Kediri menyebutkan bahwa :

1. Ketepatan Sasaran Program

Berdasarkan hasil wawancara yang telah dilakukan peneliti dengan anggota KRPL Subur Makmur untuk menggali data, menunjukkan bahwa ketetapan sasaran program KRPL sudah efektif. Menurut anggota yang telah menjadi informan, menganggap bahwa sasaran dari program KRPL yaitu ibu rumah tangga yang dapat digunakan sebagai sasaran utama dalam program KRPL, sebab ibu rumah tangga dinilai memiliki kesibukan yang lebih sedikit daripada para ibu yang bekerja, sehingga akan memiliki banyak waktu untuk merawat tanamannya.

2. Sosialisasi Program

Sosialisasi dilakukan sesuai dengan tujuan agar tujuan dari suatu rencana kegiatan dapat dipahami dan terlaksana dengan baik. Sosialisasi ini ditujukan kepada kelompok sasaran, tokoh masyarakat dan instansi pelaksana. Berdasarkan hasil pemaparan yang diberikan oleh Ibu Winarni ketua KRPL di Desa Kampung Dalem, sosialisasi telah dilaksanakan dengan jumlah dua kali pertemuan. Pada sosialisasi pertama yaitu memperkenalkan bagaimana program KRPL tersebut akan dilaksanaka serta beberapa pengetahuan lainnya mengenai KRPL. Sosialisasi diberikan langsung oleh pihak Koordinator Penyuluhan Pertanian dan Ketahanan Pangan (P2KP) Kota Kediri. Dari sosialisasi akhirnya semangat anggota kelompok Subur Makmur mulai meningkat, serta memperoleh ilmu baru yang akan diimplementasikan.

Sosialisasi selanjutnya sosialisasi yang kedua diadakan melalui tingkat Kelurahan, maka dari itu pada sosialisasi kedua ini berada di Aula Kelurahan Kampung Dalem Kota Kediri. Dalam sosialisasi ini dihadiri langsung oleh Kepala Dinas Pertanian dan Pangan Kota Kediri sekaligus menjadi pembicara untuk berpartisipasi guna memahami maksud, tujuan, dan manfaat yang akan dilakukan. Dalam sosialisasi didukung melalui beberapa metode yaitu, metode media sosial media berupa brosur ataupun pamflet yang dapat memberikan kemudahan peserta dalam memahami program KRPL, selain itu terdapat metode ceramah dan metode berlatih lapangan. Faktor positif lain yang meningkatkan 
JoIE: Journal of Islamic Economics | Silvia Devi Sugiarto, Nurul Ahsin

P-ISSN : 2807-7377

E-ISSN : 2807-7091

optimisme terhadap keberlangsungan kegiatan ini adalah dukungan penuh kepala desa terhadap kegiatan masyarakat.

3. Tujuan Program

Berdasarkan wawancara yang telah dilakukan dengan sepuluh anggota perwakilan kelompok KRPL Subur Makmur, menunjukkan bahwa tujuan program KRPL ini sangat efektif untuk kebutuhan panggan rumah tangga. Dengan adanya program Kawasan Rumah Pangan Lestari (KRPL), anggota dan masyarakat dapat menikmati manfaat dari hasil pada saat waktu panen tiba, serta memiliki kemampuan mengembangkan budidaya tanaman sayuran, buah, dan toga, serta peternakan ikan.

4. Pemantauan Program

Dalam suatu program suatu pemantauan program menjadi hal yang sangat penting guna mendukung keberlanjutan suatu program tersebut. Berdasarkan wawancara yang telah dilakukan peneliti dengan sepuluh anggota perwakilan kelompok KRPL Subur Makmur, menunjukkan bahwa pemantauan program KRPL di Kelurahan Kampung Dalem kurang efektif. Hal ini karena kurangnya pemantauan Petugas Petugas Pendamping Kota dan pendamping setelah mengikuti perlombaan. Hal ini menunjukkan terputusnya kegiatan pemantauan yang dilakukan oleh koordinator dan pemerintah kota, terutama pada musim hujan ketika anggota mengeluh tentang kematian tanaman. Pemantauan tidak hanya dilakukan diawal rencana, tetapi juga setiap saat berdasarkan isi yang telah ditentukan, sehingga anggota kelompok KRPL Subur Makmur dapat melaksanakan rencana sederhana ini secara nyata dan berkelanjutan dalam menfaatkan pekarangan.

Adapun analisis yang dilakukan peneliti melalui observasi dan wawancara, terdapat beberapa faktor yang mungkin menjadi kelebihan dan kekurangan dalam implementasi rencana KRPL di Desa Kampungg Dalem Kota Kediri :

1. Kekuatan Pelaksanaan Program KRPL di Kelurahan Kampung Dalem

a. Sasaran utama program KRPL sudah efektif.

b. Sosialisasi yang efektif, sehingga membawa dampak yang baik terhadap pelaksanaan program KRPL.

c. Manfaat program KRPL dapat dirasakan oleh anggota KRPL.

d. Ilmu mengenai pembudidayaan tanaman dapat dimiliki oleh anggota KRPL Subur Makmur.

2. Kelemahan Program KRPL di Kelurahan Kampung Dalem 
JoIE: Journal of Islamic Economics | Silvia Devi Sugiarto, Nurul Ahsin

P-ISSN : 2807-7377

E-ISSN : 2807-7091

a. Kurangnya pemantaun dari pihak luar.

b. Seiring berjalannya waktu anggota KRPL mengalami kejenuhan.

\section{KESIMPULAN}

Melalui hasil dari penelitian dan pembahasan yang sudah dijalankan melalui observasi, sertawawancara dengan anggota KRPL Subur Makmur mengenai bagaimana efektivitas program Kawasan Rumah Pangan Lestari (KRPL). Dapat diambil kesimpulan bahwa program KRPL tersebut telah berjalan dengan efektif di lingkungan Kelurahan Kampung Dalem Kota Kediri. Hal ini berdasarkan data yang diperoleh melalui wawancara yang selanjutnya dianalisis menunjukkan efektivitas Program Kawasan Rumah Pangan Lestari (KRPL) Subur Makmur telah dilakukan dengan efektif. Beberapa aspek yang dinilai dapat menjadi faktor pendukung dalam program KRPL yaitu sasaran program yang dinilai dengan efektif, metode sosialisasi yang digunakan efisien dan efektif, kemampuan anggota KRPL dalam melaksanakan program KRPL, pemanfaatan hasil dari KRPL yang dapat dirasakan langsung oleh anggota sebagai kebutuhan pangan rumah tangga. Namun ada kelemahan yang dapat dirasakan oleh anggota KRPL Subur Makmur yaitu kurangnya pemantauan program KRPL, sehingga anggota merasa tidak adanya perkembangan yang berlanjut.

\section{REFERENSI}

Kurniawan, Y. Y., Daerobi, A., Sarosa, B., \& Pratama, Y. P. (2018). Analisis program kawasan rumah pangan lestari dan hubungannya dengan ketahanan pangan serta kesejahteraan. Jurnal Ilmu Ekonomi Terapan, 03(2), 1-22. https://ejournal.unair.ac.id/JIET/article/view/8451

Mayusa, T. tivani, Zakiah, Z., Zakiah, Z., Romano, R., \& Romano, R. (2018). Efektivitas Program Pemerintah Kawasan Rumah Pangan Lestari (KRPL) terhadap Pola Pangan Harapan Rumah Tangga di Kota Banda Aceh. Jurnal Ilmiah Mahasiswa Pertanian, 3(4), 308-320. https://doi.org/10.17969/jimfp.v3i4.9299

Oka, I., Darmawan, Dwi., Astiti, N. (2016). Keberhasilan Program Kawasan Rumah Pangan Lestari (KRPL) pada Kelompok Wanita Tani di Kabupaten Gianyar. Jurnal Manajemen Agribisnis, 4(2), 133-146.

Pembangunan, P. (2017). EFEKTIVITAS PENGGUNAAN DANA DESA DALAM PENINGKATAN PEMBANGUNAN (Suatu Studi Di Desa Watutumou Dua Kecamatan Kalawat Kabupaten Minahasa Utara). Jurnal Eksekutif, 2(2). 
JoIE: Journal of Islamic Economics | Silvia Devi Sugiarto, Nurul Ahsin

P-ISSN : 2807-7377

E-ISSN : 2807-7091

Purwami, I., Irawati, M. H., Susilowati, S., \& Budiasih, E. (2018). Program Kawasan Rumah Pangan Lestari (KRPL): Analisis Pengetahuan Lingkungan dan Sikap Peduli Lingkungan Santri Pondok Pesantren di Kecamatan Gading Kabupaten Probolinggo. Bioeksperimen: Jurnal Penelitian Biologi, 4(2), 16-21. https://doi.org/10.23917/bioeksperimen.v4i2.6881

Rahmawati, R., \& Parangu, K. A. (2021). Potensi Pemulihan Pariwisata Halal di Ponorogo (Analisa Strategi Pada Masa Pandemi Covid-19). JoIE: Journal of Islamic Economics, 1(1).

Sholehah, N., Irawati, M., \& Sueb, S. (2016). Kawasan Rumah Pangan Lestari (KRPL): Analisis Pengetahuan dan Perilaku Santri. JPS (Jurnal Pendidikan Sains), 4(4), 152-156. Tamara, A., Yusuf, M. N., \& Setia, B. (2020). Implementasi Program Kawasan Rumah Pangan Lestari (Krpl) Di Desa Ciganjeng Kecamatan Padaherang Kabupaten Pangandaran. Jurnal Ilmiah Mahasiswa Agroinfo Galuh, 7(3), 770. https://doi.org/10.25157/jimag.v7i3.4015 